\title{
Bilateral Iris Coloboma Revealed by a Decreased Vision: About the First Case in Togo Observed in Kara University Teaching Hospital
}

\author{
Kokou Messan Amedome1 ${ }^{*}$, Codjo Rodrigue Abel Assavédo², Yao Ako Patrick Mensah"1, \\ Kossi Dzidzinyo3 ${ }^{3}$, Kokou Vonor ${ }^{4}$, Koffi Didier Ayéna ${ }^{5}$, Komi Balo ${ }^{3}$ \\ ${ }^{1}$ Centre Hospitalier Universitaire de Kara, Kara, Togo \\ ${ }^{2}$ Centre hospitalier départemental Borgou-Alibori, Parakou, Benin \\ ${ }^{3}$ Centre Hospitalier Universitaire Sylvanus Olympio, Lomé, Togo \\ ${ }^{4}$ Centre Hospitalier Régional de Kara Tomdè, Kara, Togo \\ ${ }^{5}$ Hôpital Secondaire de Bè, Lomé, Togo \\ Email: *amedomekokoumessan@gmail.com
}

How to cite this paper: Amedome, K.M., Assavédo, C.R.A., Mensah, Y.A.P., Dzidzinyo, K., Vonor, K., Ayéna, K.D. and Balo, K. (2021) Bilateral Iris Coloboma Revealed by a Decreased Vision: About the First Case in Togo Observed in Kara University Teaching Hospital. Open Journal of Ophthalmology, $11,249-252$.

https://doi.org/10.4236/ojoph.2021.114020

Received: June 16, 2021

Accepted: September 12, 2021

Published: September 15, 2021

Copyright $\odot 2021$ by author(s) and Scientific Research Publishing Inc. This work is licensed under the Creative Commons Attribution International License (CC BY 4.0).

http://creativecommons.org/licenses/by/4.0/

\begin{abstract}
Background: Ocular coloboma is the product of an error in the fetal fissure closure, normally occurring between the fifth and sixth weeks of gestation [1]. It may involve the cornea, iris, zonula, ciliary body, choroid, retina and optic nerve. The incidence of this syndrome is 0.7 per 10,000 live-births [1]. The aim of this observation is to present the first case of bilateral coloboma of the iris [1]. This case was associated with an ametropia causing a decrease in visual acuity. Case Presentation: This was a clinical observation concerning a young 12-year-old patient who consulted for blurring of vision which had progressed for approximately 2 years. The ophthalmologic examination revealed an ametropia with a bilateral notch of the pupillary rim suggesting a bilateral coloboma. There was no association with another coloboma such as chorioretinal coloboma which is quite common and is accompanied frequently by visual symptoms. Conclusion: A visual impairment of the child can indicate ametropia. However, other congenital anomalies can be discovered as was the case in this clinical observation.
\end{abstract}

\section{Keywords}

Coloboma, Iris, Decreased Vision, Kara, Togo

\section{Introduction}

Ocular coloboma is the product of an error in the fetal fissure closure, normally 
occurring between the fifth and sixth weeks of gestation [1]. It may involve the cornea, iris, zonula, ciliary body, choroid, retina and optic nerve [1]. The incidence of this syndrome is 0.7 per 10,000 live-births [1]. Other inherited autosomal dominant and recessive syndromes and non-inherited syndromes have been linked to this finding. Other ocular conditions like cataracts, lens subluxation, secondary glaucoma, amblyopia, strabismus and anisometropia have been related to this developmental defect [1]. Through this observation, we describe the first case of bilateral iris coloboma associated with reduced visual acuity.

\section{Case Presentation}

It was about a 12-year-old girl who consulted in the ophthalmology department of the University Teaching Hospital of Kara for visual blurring in class who has been evolving for 6 months. There was no notion of eye pain, nor associated eye redness and headache. In the history of his illness, the beginning dates back to 6 months earlier, marked by the occurrence of visual blurring in class during lessons and especially when it was a matter of copying the lessons into the notebook. No consultation was made and it was in view of the persistence of signs that the patient consulted in ophthalmology in the Kara University Hospital for better care. In the antecedents chapter, there was no particular antecedent.

On examination, there were no visible morphological abnormalities. Ophthalmologically, in the right eye: distance visual acuity was 20/50 without correction and Parinaud 2 near but 20/20 with a correction of -0.50 . There was no disturbance of the statics or the palpebral dynamics. Slit lamp examination noted good conjunctival staining, transparent cornea, optically empty anterior chamber. At the level of the pupil, there was a pear-shaped deformation of the pupil with a notch at the bottom (Figures 1-3). The photomotor reflex was present and normal. The lens was normal and transparent as was the normal pupillary glow. The inraocular pressure was $14 \mathrm{mmhg}$. Examination of the left eye noted distant visual acuity of 20/40 and Parinaud 2 up close but 20/20 with a correction of $+0.50(-1.75) 10^{\circ}$. The slit lamp examination was identical to the right eye. Intraocular pressure was $18 \mathrm{mmhg}$. The fundus examination did not reveal any abnormality in either the papillae or the chorio-retina.

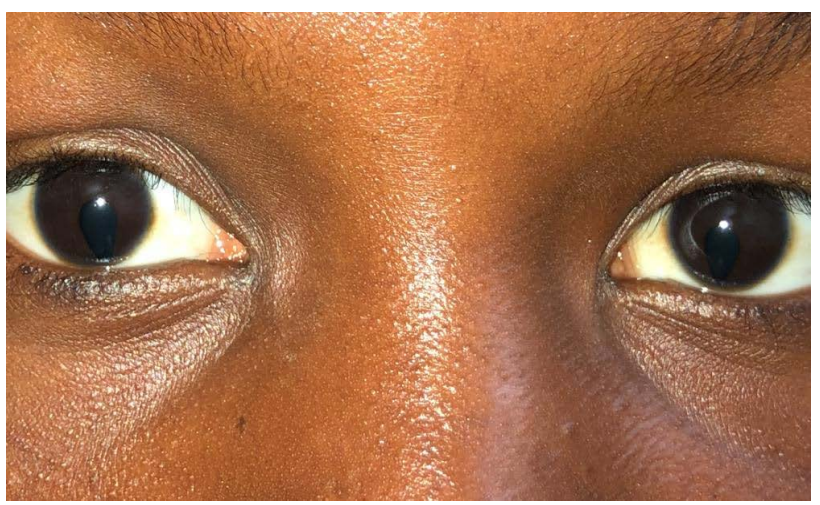

Figure 1. Bilateral iris coloboma in a 12-year-old girl. 


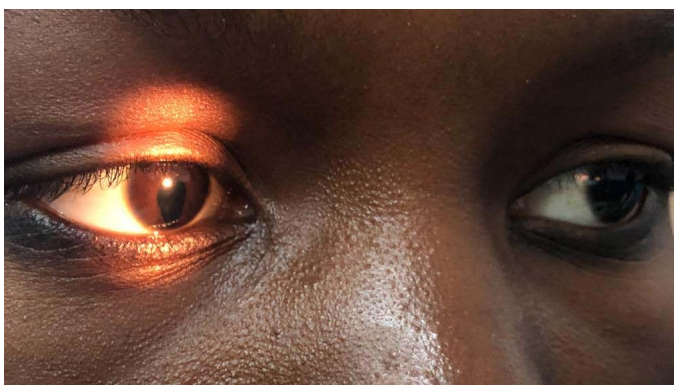

Figure 2. Right eye coloboma.

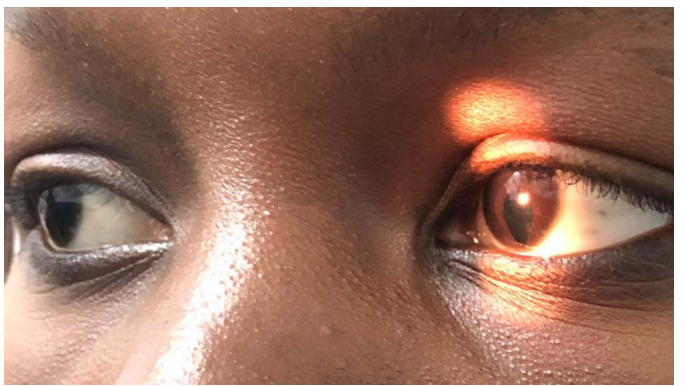

Figure 3. Left eye coloboma.

The diagnosis of bilateral coloboma of the iris associated with ametropia was retained. The patient underwent an optical correction which resulted in a final visual acuity of 10/10 in each eye. The correction was also therefore prescribed which resulted in a disappearance of the visual blur.

\section{Discussion}

Coloboma is due to a failure to close the colobomic slit around the 5 - 7 th week of life, when the embryo is 7 to $14 \mathrm{~mm}$ in size. This is the period during which we witness the invagination of the optic vesicle and the closure of the fetal slit. Iris colobomas often do not cause abnormal vision and only have cosmetic inconvenience. It is the association with a chorio-retinal coloboma that causes severe disturbances of vision as some authors have described it [2] [3].

Presence of typical iris and retinochoroidal coloboma is a relatively common finding resulting from the failure of the choroidal fissure closure during embryogenesis [4]. However, in this case, there is no association with chorio-retinal coloboma. An iris coloboma may not have any consequences on vision, as a posterior coloboma (chorioretinal and/or papillary) will often be accompanied by poor vision that cannot be improved. In our specific case, an improvement in vision by optical correction confirms the isolated nature of this coloboma even in the absence of an examination of the fundus. The most classic typical form is the infero-nasal iris coloboma. In this specific case, they are inferior. A coloboma can be complete and involve the entire thickness of the iris (epithelium and stroma) or be incomplete and only affect part of the thickness of the iris. A coloboma can be total and lead to an opening up to the root of the iris in a "keyhole", or else partial and only give a deformation of the pupil which is then no 
longer round. Here it is a complete but partial coloboma which explains the deformation of the pupil.

Compared to complications, iris colobomas are not accompanied by complications. Colobomas may or may not be associated with systemic abnormalities. Syndromic forms are of two types: CHARGE (Coloboma, Heart defect, Atresia choanae, Retarded growth and development, Genital hypoplasia, and Ear anomalies/deafness) and $\mathrm{COACH}$ (Cerebellar vermis hypoplasia, Oligophrenia, Ataxia, Coloboma, and Hepatic fibrosis) syndromes [5]. In our case, no systemic association was noted.

\section{Conclusion}

Bilateral iris coloboma is a rare entity. Improved visual acuity may be a factor for a good prognosis, indicating an absence of association with other posterior segment colobomas or a systemic abnormality as in the present observation.

\section{Declaration of Patient Consent}

The authors certify that they have obtained all appropriate patient consent forms. In the form the patient has given her consent for her images and other clinical information to be reported in the journal. The patient understands that her name and initials will not be published and due efforts will be made to conceal her identity.

\section{Conflicts of Interest}

The authors declare no conflicts of interest regarding the publication of this paper.

\section{References}

[1] Galvis, V., Tello, A., Valarezo, P., et al. (2013) Iris Coloboma in One Eye and Pigment Dispersion Syndrome in the Fellow Eye. Case Reports, 2013, bcr 2013009733. https://doi.org/10.1136/bcr-2013-009733

[2] Kumar, N., Valliappan, A. and Bansal, R. (2020) Unusual Superior Iris and Retinochoroidal Coloboma. Indian Journal of Ophthalmology, 68, 921. https://doi.org/10.4103/ijo.IJO 187619

[3] Cours du Syndicat national des ophtalmologistes de France (SNOF). https://www.snof.org/encyclopedie/colobomes

[4] Uhumwangho, O.M. and Jalali, S. (2014) Chorioretinal Coloboma in a Paediatric Population. Eye, 28, 728-733. https://doi.org/10.1038/eye.2014.61

[5] George, A., Cogliati, T. and Brooks, B.P. (2020) Genetics of Syndromic Ocular Coloboma: CHARGE and COACH Syndromes. Experimental Eye Research, 193, 107940. https://doi.org/10.1016/j.exer.2020.107940 